\title{
Identification of simple sequence repeat markers for sweetpotato weevil resistance
}

\author{
Benard Yada $\cdot$ Agnes Alajo • Gorrettie N. Ssemakula • Gina Brown-Guedira • \\ Milton Anyanga Otema - Philip C. Stevenson - Robert O. M. Mwanga • \\ G. Craig Yencho
}

Received: 25 January 2017/ Accepted: 19 May 2017/Published online: 10 June 2017

(C) The Author(s) 2017. This article is an open access publication

\begin{abstract}
The development of sweetpotato [Ipomoea batatas (L.) Lam] germplasm with resistance to sweetpotato weevil (SPW) requires an understanding of the biochemical and genetic mechanisms of resistance to optimize crop resistance. The African sweetpotato landrace, 'New Kawogo', was reported to be moderately resistant to two species of SPW, Cylas puncticollis and Cylas brunneus. Resistance has been associated with the presence of hydroxycinnamic acids esters (HCAs), but the underlying genetic basis remains unknown. To determine the genetic basis of this resistance, a bi-parental sweetpotato population from a cross between the moderately resistant, whitefleshed 'New Kawogo' and the highly susceptible, orange-fleshed North American variety 'Beauregard' was evaluated for SPW resistance and genotyped with simple sequence repeat (SSR) markers to identify
\end{abstract}

B. Yada $\cdot$ G. Craig Yencho $(\bowtie)$

Department of Horticultural Science, North Carolina State University, 214 Kilgore Hall, Box 7609, Raleigh, NC 27695-7609, USA

e-mail: craig_yencho@ncsu.edu

B. Yada · A. Alajo - G. N. Ssemakula - M. A. Otema National Agricultural Research Organization (NARO),

National Crops Resources Research Institute (NaCRRI),

Namulonge, P.O. Box 7084, Kampala, Uganda

G. Brown-Guedira

USDA-ARC, Department of Crop Science, North

Carolina State University, 4114 Williams Hall,

Box 7620, Raleigh, NC 2769, USA weevil resistance loci. SPW resistance was measured on the basis of field storage root SPW damage severity and total HCA ester concentrations. Moderate broad sense heritability $\left(\mathrm{H}^{2}=0.49\right)$ was observed for weevil resistance in the population. Mean genotype SPW severity scores ranged from 1.0 to 9.0 and 25 progeny exhibited transgressive segregation for SPW resistance. Mean genotype total HCA ester concentrations were significantly different $(\mathrm{P}<0.0001)$. A weak but significant correlation $(\mathrm{r}=0.103, \mathrm{P}=0.015)$ was observed between total HCA ester concentration and SPW severity. A total of five and seven SSR markers were associated with field SPW severity and total HCA ester concentration, respectively. Markers IBS11, IbE5 and IbJ544b showed significant association with both field and HCA-based resistance,

M. A. Otema - P. C. Stevenson

Natural Resources Institute, University of Greenwich, Chatham Maritime, Kent ME4 4TB, UK

R. O. M. Mwanga

International Potato Center (CIP), Naguru Hill, Katalima

Road, Plot 106, Box 22274, Kampala, Uganda

M. A. Otema - P. C. Stevenson

Royal Botanic Gardens, Kew, Surrey TW9 3AB, UK 
representing potential markers for the development of SPW resistant sweetpotato cultivars.

Keywords Hydroxycinnamic acid - SSR markers . Sweetpotato weevil

\section{Introduction}

Sweetpotato [Ipomoea batatas (L.) Lam] is a rich source of carbohydrates, vitamin A, vitamin C, fiber, and minerals (Woolfe 1992; Teow et al. 2007). It is one of the most affordable and nutrient rich among the root and tuber crops in the developing world, and it is particularly important in sub-Saharan Africa (SSA) (Low et al. 2007). The consumption of orange-fleshed varieties rich in $\beta$-carotene has been shown to improve the vitamin A status of children and women in SSA (van Jaarsveld et al. 2005; Hotz et al. 2012). This, coupled with its ability to yield under marginal soil conditions, with minimal input requirements makes sweetpotato a key crop in the food systems of many SSA countries (Karyeija et al. 1998).

Despite the importance of the crop, average sweetpotato storage root yields in SSA are low, about 4.0-10.0 metric t/ha compared to the average root yield of 21.5 metric t/ha in China, the leading global producer of the crop (FAOSTAT 2014). Apart from poor crop management practices, a major reason for low storage root yields in SSA is due to sweetpotato weevil (SPW), which can cause complete yield losses during dry spells (Smit 1997).

The sweetpotato weevil species, Cylas puncticollis (Boheman) and Cylas brunneus (Fabricius) predominantly occurring in Africa, severely reduce the production and market value of sweetpotato in SSA (Stathers et al. 2003). The major damage is inflicted on the storage roots by larval feeding (Cockerham et al. 1954; Jansson et al. 1987). Secondary pathogen infection and induction of sesquiterpenes produced in response to damage makes the storage roots bitter and unacceptable for consumption (Uritani et al. 1975; Sato and Uritani 1981).

The concealed feeding behavior of SPWs makes their management difficult (Nottingham and Kays 2002; Odongo et al. 2003). Host plant resistance is a major component of any integrated pest management (IPM) program, but to date, the development of weevil resistant varieties has not been successful in SSA. This is attributed to the complex nature of the sweetpotato genome making crop improvement difficult, limited sources of resistance and lack of knowledge on the genetics of inheritance of sweetpotato weevil resistance even where resistance mechanisms have been identified (Stevenson et al. 2009).

Recently, a wide range of sweetpotato genotypes were screened for SPW resistance and compared with a highly susceptible cultivar, I. batatas 'Tanzania', as a control to identify the biochemical basis of SPW resistance (Muyinza et al. 2012; Anyanga et al. 2013). Considerable variation in the concentrations of hydroxycinnamic acid (HCA) esters in the screened genotypes was recorded with the highest concentration observed in 'New Kawogo', an African landrace originating from Uganda. The six HCA esters associated with SPW resistance were identified as hexadecylcaffeic acid, hexadecylcoumaric acid, heptadecylcaffeic acid, octadecylcaffeic, octadecylcoumaric acid and 5-0-caffeoylquinic acids (Stevenson et al. 2009; Anyanga et al. 2013). Their constitutive production in sweetpotato, particularly at the root surface, was established as one of the quantifiable chemical bases of SPW resistance (Anyanga et al. 2013). Development of a rapid chemotyping method for hydroxycinnamic acid esters (HCA), and/or molecular markers linked to them was proposed in as a tool for selecting SPW resistance using markerassisted selection (MAS) and/or biochemistry-assisted selection.

Our knowledge on the inheritance of SPW resistance is limited. While linkage and QTL analysis of storage root yield, dry matter, starch, $\beta$-carotene content and root-knot nematode resistance have been reported in sweetpotato (Cervantes-Flores et al. 2008a, b; Chang et al. 2009; Cervantes-Flores et al. 2011; Zhao et al. 2013), none has yet been reported for SPW resistance.

Development of biochemical and genomic tools to unravel the chemical and genetic basis of resistance to SPW in 'New Kawogo' will facilitate the development of SPW resistant germplasm and cultivars. The application of functional genomics in insect ecology has been widely reviewed by Tittiger (2004). Nextgeneration sequencing will also contribute to simple sequence repeat (SSR) and single nucleotide polymorphism (SNP) marker discovery for use in marker assisted selection (MAS) and genomic selection for developing SPW resistant cultivars. With the low 
number of sweetpotato SSR markers published to date compared to other major crops (Buteler et al. 1999; Hu et al. 2004; Schafleitner et al. 2010; Wang et al. 2011), and no SNPs at all, genomic improvement of SPW resistance is still in its infancy.

In this study, we used logistic regression to associate published SSR markers (Buteler et al. 1999; Hu et al. 2004; Schafleitner et al. 2010; Wang et al. 2011) to SPW resistance in the 'New Kawogo' $x$ 'Beauregard' bi-parental population, which is segregating for SPW resistance and other agronomic traits. This is the first time that co-dominantly inherited SSR markers have been used to identify SPW resistance loci in sweetpotato. As more sweetpotato SSR and SNP markers are developed, genomic SPW resistance breeding might be implemented in the future.

\section{Materials and methods}

Plant material

The population used in this study consisted of $287 \mathrm{~F}_{1}$ progeny from a bi-parental cross between 'New Kawogo' (NK) and 'Beauregard' (B) generated at NaCRRI in Uganda $\left(0^{\circ} 32^{\prime} \mathrm{N}, 32^{\circ} 35^{\prime} \mathrm{E}, 1150\right.$ m.a.s.l). 'New Kawogo' (female) is a moderately SPW and sweetpotato virus disease (SPVD) resistant, high dry matter content, white-fleshed released Ugandan cultivar (Mwanga et al. 2001; Stevenson et al. 2009). 'Beauregard' (male) is a SPW and SPVD susceptible, low dry matter content and orange-fleshed (high $\beta$ carotene content) US cultivar (Rolston et al. 1987).

Genomic DNA extraction and SSR genotyping

Genomic DNA was extracted from the young leaves (ca. $100 \mathrm{~g}$ ) of each progeny and parents using a modified C-TAB method (Doyle and Doyle 1990) and quantified using a NanoDrop ND-1000 spectrophotometer (NanoDrop Technologies, Wilmington, Delaware) at the NaCRRI Biosciences laboratory. The DNA samples were then shipped to North Carolina State University for genotyping.

The sequences of 405 published expressed sequence tags (EST) SSR primers (Buteler et al. 1999; Hu et al. 2004; Schafleitner et al. 2010; Wang et al. 2011) were obtained for this study. The primers were redesigned by addition of the M13 tail universal primer sequence (TGTAAAACGACGGCCAGT) to the $5^{\prime}$ end of the forward primer sequence and then synthesized by Eurofins Genomics (Huntsville, Alabama). The complementary M13 sequence was fluorescently labeled with VIC (green), 6FAM (blue), NED (yellow) and PET (red) tags from Applied Biosystems (Foster City, California) for automated detection of polymerase chain reaction (PCR) products.

The genomic DNA was amplified using polymerase chain reaction (PCR) performed in a $10 \mu$ reaction volume. The PCR reaction consisted of $3.0 \mu \mathrm{l}$ (20-40 ng/ $\mu \mathrm{l}$ ) DNA template, $1.0 \mu \mathrm{l}$ 10X PCR buffer, $1.0 \mu 115 \mathrm{mM} \mathrm{MgCl} 2,0.8 \mu \mathrm{l} 10 \mathrm{mM}$ DNTPs mix, $0.2 \mu \mathrm{l}$ forward primer $(1.0 \mu \mathrm{M}), 1.0 \mu \mathrm{l}$ reverse primer $(1.0 \mu \mathrm{M}), 0.5 \mu \mathrm{l} \mathrm{M} 13$ primer $(1.0 \mu \mathrm{M}), 0.1 \mu \mathrm{l}$ Taq polymerase $(50 \mathrm{U} / \mu \mathrm{l})$ and $2.4 \mu \mathrm{l} \mathrm{PCR}$ water. The PCR conditions were as follows; one hold at $94.0{ }^{\circ} \mathrm{C}$ for $4 \mathrm{~min}$, followed by first 15 cycles of $94.0^{\circ} \mathrm{C}$ denaturation for $30 \mathrm{~s}, 55.0^{\circ} \mathrm{C}$ annealing for $30 \mathrm{~s}$, and $72.0^{\circ} \mathrm{C}$ extension for $1 \mathrm{~min}$, then followed by 25 cycles of $94.0{ }^{\circ} \mathrm{C}$ for $30 \mathrm{~s}, 50.0{ }^{\circ} \mathrm{C}$ annealing for $30 \mathrm{~s}$, and $72.0{ }^{\circ} \mathrm{C}$ extension for $1 \mathrm{~s}$, followed by two holds at $72.0{ }^{\circ} \mathrm{C}$ for $7 \mathrm{~min}$, and at $4.0{ }^{\circ} \mathrm{C}$ for infinite time.

The PCR amplifications were performed using an Eppendorf Mastercycler (Eppendorf AG, Hamburg, Germany). We did PCR product sizing by capillary electrophoresis using an ABI3730xl Genetic Analyzer (Applied Biosystems, Foster City, California). The allele data was analyzed using GeneMarker 2.2.0 (SoftGenetics, State College, Pennsylvania). Allele scores were converted to binary data, with 1 being allele present and 0 as allele absent. Details of DNA extraction and PCR were described in Yada et al. (2015).

Field trials and SPW resistance screening

The 287 progeny and parents were evaluated for SPW resistance at three sites and two seasons in Uganda during 2012-2013. All experiments were arranged in a randomized complete block design with 3 replications per genotype per site. Each experimental plot consisted of five plants spaced $30 \mathrm{~cm}$ apart planted on ridges separated by $1.0 \mathrm{~m}$.

The trials were conducted at the National SemiArid Resources Research Institute (NaSARRI) $\left(1^{\circ} 32^{\prime} \mathrm{N}, 33^{\circ} 27^{\prime}\right.$ E), Ngetta Zonal Agricultural Research and Development Institute (NgeZARDI) 
$\left(2^{\circ} 202^{\prime} \mathrm{N}, 33^{\circ} 62^{\prime} \quad \mathrm{E}\right)$, and the National Crops Resources Research Institute (NaCRRI) $\left(0^{\circ} 32^{\prime} \mathrm{N}\right.$, $\left.32^{\circ} 35^{\prime} \mathrm{E}\right)$.

The trials were artificially infested with 20 weevils per plot $(7$ female and 3 male sweetpotato weevils each of $C$. puncticollis and C. brunneus) at 90 days after planting to increase the weevil population, and to optimize and even the infestation across the study sites as previously reported (Muyinza et al. 2012). The weevils were reared on storage roots in the laboratory at NaCRRI.

During the first season (2012A), the trials were planted in June, 2012 and harvested in November, 2012. The second season trials (2012B) were planted in November, 2012 and harvested in May, 2013. The harvesting of both trials was done at 5-6 months after planting to allow ample time for SPW infestation.

We inspected the harvested storage roots and scored SPW severity using a 1-9 scale, where $1=$ no weevil damage symptoms, $2=$ unclear weevil damage symptoms, $3=$ clear weevil damage symptoms $<5 \%$ of roots per plot, $4=$ clear weevil damage symptoms at $6-15 \%$ of roots per plot, $5=$ clear weevil damage symptoms at $16-33 \%$ of roots per plot, $6=$ clear weevil damage symptoms in $34-66 \%$ of roots per plot (more than $1 / 3$, less than $2 / 3$ ), $7=$ clear weevil damage symptoms in $67-99 \%$ of roots per plot ( $2 / 3$ to almost all), $8=$ clear weevil symptoms in all roots per plot, $9=$ severe weevil damage symptoms in all roots per plot (rotting) as described in Grüneberg et al. (2010).

\section{Hydroxycinnamic acid (HCA) ester profiling}

Storage root samples were brought to NaCRRI and a sub-sample of storage roots from each plot was washed under running tap water and processed. We selected 289 genotypes (287 progeny and 2 parents) from NaCRRI and NgeZARDI for HCA analysis. Fresh roots were cut transversely into 2-3 root discs from the middle portion of each root sample, weighed and freeze-dried using a vacuum freeze dryer (TrueTen Industrial Co. Taichung City, Taiwan) for $72 \mathrm{~h}$. The periderm and epidermal sections of the freezedried root disks were using the edge of a kitchen knife. The separated portions were powdered using a laboratory blender. The freeze-dried samples were weighed and milled at NaCRRI using a Thomas Wiley Mini-Mill (Thomas Scientific, Swedesboro,
New Jersey). For HCA extraction, $50 \mathrm{mg}$ of the powdered samples were immersed in methanol $(1 \mathrm{ml})$ in $1.5 \mathrm{ml}$ Eppendorf tubes for $24 \mathrm{~h}$. The crude mixture was spun using a mini-centrifuge (BIO-RAD, Hercules, California) at $13,000 \mathrm{rpm}$ for $5 \mathrm{~min}$ and the supernatant collected for liquid chromatography-mass spectrometry (LC-MS) analysis as described by Anyanga et al. (2013). The profiling of HCA ester concentration was done at the Natural Resources Institute (NRI), University of Greenwich, UK.

Data analysis

All data analysis was performed using 284 progeny and the parents. Analysis of variance (ANOVA) of SPW resistance was conducted using the generalized linear mixed model procedure, PROC GLIMMIX (SAS 9.4, SAS Institute, Cary, North Carolina). We treated the genotypes as fixed effects and block, site and season as random effects. We compared the overall SPW least significant (LS) means of parents to that of progeny (Gtype), and also the individual progeny and parents LS means Gen (Gtype) across sites and seasons using the Turkey-Kramer grouping $(\alpha=0.05)$. The genotype means were used to assess the level of transgressive segregation for SPW resistance.

Using PROC MIXED and PROC IML (SAS 9.4, SAS Institute, Cary, North Carolina), we analyzed the phenotypic and genotypic variances for SPW severity scores, which were later used to compute the broad sense heritability of SPW resistance in this population.

For total storage root HCA ester concentration, analysis of variance was done using PROC GLM with sites as replications. We used the genotype LS means for assessing the level of transgressive segregation for HCA ester production in the population. The Pearson correlation analysis of field SPW severity and HCA ester production of genotypes was done through PROC CORR (SAS 9.4, SAS Institute, Cary, North Carolina).

For marker and trait association analyses, we used a total of 133 informative SSR markers out of the 405 markers screened. The SSR markers associated with SPW resistance were identified using regression analysis. We used the genotype best linear unbiased predictions (BLUPs) of SPW resistance and HCA content to identify SSR markers associated with sweetpotato weevil resistance. The genotype SPW 
resistance BLUPs were analyzed using PROC MIXED (SAS 9.4, SAS Institute, Cary, North Carolina). Then SSR loci and trait regression analysis was conducted using PROC GLIMMIX with genotypes as fixed effects. An SSR marker locus was considered to have significant association with SPW resistance if $\mathrm{p}<0.05$ for the regression analysis.

\section{Results}

Analysis of variance (ANOVA) of SPW resistance

Sites had significant effects $(\mathrm{p}<0.05)$ on SPW resistance of the genotypes as the mean SPW severity at NaCRRI, NgeZARDI and NaSARRI were 3.6, 2.1 and 5.4, respectively. The genotype $\mathrm{x}$ environment $(\mathrm{G}$ $x$ E) interaction effect was also significant for SPW resistance in this population. The mean SPW resistance of the parents compared to that of progeny (Gtype) as estimated by SPW severity scores on storage roots was not significant, but differences in mean SPW resistance of individual progeny and individual parents (Gen(Gtype)) across sites and seasons was significant (Table 1).

Genotype performance and heritability

The mean genotype SPW severity scores across seasons at NaCRRI ranged from 1.0 to 9.0, with a mean of 3.6 for both seasons (Fig. 1a), with mean SPW severity for 'New Kawogo' and 'Beauregard' of 2.1 and 7.5, respectively. A total of 18 progeny performed better than 'New Kawogo', the resistant parent for SPW resistance at NaCRRI. The top five most resistant progeny in terms of mean SPW severity at NaCRRI were; NKB84, NKB52, NKB280, KNB219 and NKB225. A total of three progeny: NKB217, NKB199 and NKB125 had higher severity scores than 'Beauregard', the susceptible parent at this site.

At NgeZARDI, mean genotype SPW severity across seasons ranged from 1.0 to 7.0 (Fig. 1b) and the mean SPW severity across seasons was 2.1. The mean SPW severity of 'New Kawogo' and 'Beauregard' were 1.4 and 7.1, respectively. The distribution of genotype performance was skewed to the right, meaning most genotypes showed low SPW damage. Twenty-seven progeny exhibited positive transgressive segregation (performed better than the resistant parent) for filed SPW resistance at this site. The top five most resistant genotypes at this site were; NKB219, NKB225, NKB52, NKB72 and NKB115. No progeny had a higher mean SPW severity than 'Beauregard' at NgeZARDI.

The mean genotype SPW severity scores across seasons at NaSARRI ranged from 2.0 to 9.0 (Fig. 1c) with a mean SPW severity of 5.4. The mean SPW severity of 'New Kawogo' and 'Beauregard' were 3.6 and 8.7, respectively. The total number of progeny exhibiting positive transgressive segregation for SPW resistance at NaSARRI was 19. The top five weevil resistant progeny at this site were; NKB219, NKB225, NKB260, NKB84 and NKB10. The progenies that performed worse than 'Beauregard' at this site were NKB17, NKB237, NKB283, NKB282 and NKB127.

Mean overall genotype SPW severity across sites and seasons ranged from 1.0 to 8.0 (Fig. 1d). The mean overall SPW severity of the parents 'New Kawogo' and 'Beauregard' were 2.5 and 7.8, respectively. The overall genotype mean SPW severity distribution was skewed to the right and a total 25 progeny showed positive transgressive segregation for overall SPW resistance. Progeny NKB152, NKB257, NKB72, NKB59 and NKB260 had the lowest overall mean SPW severity across sites and seasons (most resistant). Progeny NKB219 and NKB225 had low mean SPW severity across the three sites having stable performance for SPW resistance.

On analyzing the genotypic and phenotypic variances, the broad sense heritability estimate for field SPW resistance in this population was moderate $\left(\mathrm{H}^{2}=0.49 \pm 0.047\right)$.

Total storage root HCA ester analysis

Mean storage root total HCA ester concentrations of genotypes (progeny and parents) were significantly different $(\mathrm{P}<0.0001)$. The overall mean total HCA ester concentration of the genotypes was $69.4 \mathrm{ng} / \mathrm{g}$ on dry weight basis. The mean total HCA ester concentrations of 'New Kawogo' and 'Beauregard' were 379.6 and $70.4 \mathrm{ng} / \mathrm{g}$, respectively. Genotype mean total HCA ester concentrations ranged from 4.9 to 379.6 ng/g, in progeny NKB175 and 'New Kawogo', respectively. The distribution of genotype mean total HCA ester concentration was skewed to the right and no progeny had higher total HCA ester concentration than 'New Kawogo', the resistant parent (Fig. 2). 
Table 1 ANOVA of sweetpotato weevil resistance in the progeny and parents of the 'New Kawogo' $\times$ 'Beauregard' mapping population

\begin{tabular}{|c|c|c|c|c|c|}
\hline Source & DF & SS & MS & $F$ value & $\operatorname{Pr}>F$ \\
\hline Site $^{\mathrm{a}}$ & 2 & 46.0 & 23.0 & 3.6 & 0.0370 \\
\hline Gtype $^{\mathrm{b}}$ & 1 & 3.6 & 3.6 & 1.4 & 0.2461 \\
\hline Gen $(\text { Gtype })^{\mathrm{c}}$ & 284 & 1580.2 & 5.6 & 2.1 & $<.0001$ \\
\hline Site*Gtype $^{\mathrm{d}}$ & 2 & 9.3 & 4.6 & 1.8 & 0.1733 \\
\hline Site*Gen(Gtype $)^{\mathrm{e}}$ & 567 & 1881.3 & 3.3 & 1.3 & 0.0001 \\
\hline Block(Site*Season) & 15 & 1538.2 & 102.5 & 38.8 & $<.0001$ \\
\hline Residual $^{\mathrm{f}}$ & 3892 & $10,284.0$ & 2.6 & & \\
\hline
\end{tabular}

Trials were conducted at three sites (NaCRRI, NgeZARDI and NaSARRI) and two seasons in a randomized complete block design (RCBD) with three replicates in Uganda in 2012

$D F$ degrees of freedom, $S S$ sum of squares, $M S$ mean sum of squares (SS/DF)

${ }^{a}$ Mean squares tests the significant effect of locations

b Tests the significant effect of overall least significant mean of the parents vs that of the progeny across sites and seasons

c Tests the significant effect of least significant means of individual genotypes (parents and progeny) across sites and seasons

${ }^{d}$ Tests the significant effect of site on overall parent and progeny least significant means

e Tests the significant effect of genotype $x$ environment interaction

${ }^{\mathrm{f}}$ Used in ANOVA to test significant effect of extraneous factors
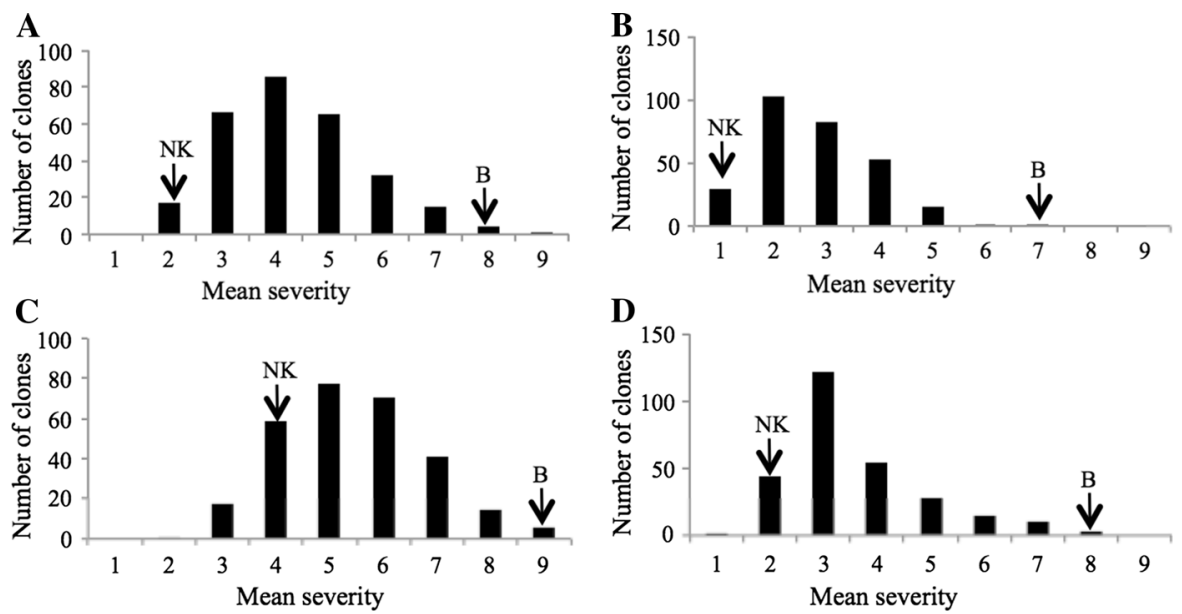

Fig. 1 Distribution of mean sweetpotato weevil severity in the progeny and parents of the 'New Kawogo' (NK) x 'Beauregard' (B) mapping population at NaCRRI (a), NgeZARDI (b), $\operatorname{NaSARRI}(\mathbf{c})$, and overall mean across sites and seasons (d),

bars represent the number of clones in each class of mean SPW severity scores averaged over seasons for sites, and averaged over sites and seasons for the overall mean

A weak significant positive correlation was observed between genotype total storage root HCA ester concentrations and field SPW severity $(\mathrm{r}=0.103, \mathrm{P}=0.015)$. The top five progeny with the highest mean total HCA ester concentration were; NKB257 (366.5 ng/g), NKB152 (357.5 ng/g), NKB108 (268.9 ng/g), NKB $256(254.0 \mathrm{ng} / \mathrm{g})$ and NKB265 (237.1 ng/g). In contrast, the progeny that showed the lowest concentration

of mean total HCA esters were; NKB175 (4.9 ng/g), NKB285 (5.0 ng/g), NKB182 (6.3 ng/g), NKB29 $(8.1 \mathrm{ng} / \mathrm{g})$ and NKB223 $(8.7 \mathrm{ng} / \mathrm{g})$.

Out of the top five best performing progeny for mean total HCA ester concentrations and SPW severities, three (NKB152, NKB257 and NKB108) showed high consistent performance on the basis of SPW severities. Out of the 25 progeny that performed 
better than 'New Kawogo' for field SPW resistance, nine had total HCA ester concentrations greater than $140 \mathrm{ng} / \mathrm{g}$. Interestingly, some highly susceptible progeny to SPW in the field such as NKB80, NKB151 and NKB283 had high HCA ester concentrations of $163.9,160.5$ and $140.6 \mathrm{ng} / \mathrm{g}$, respectively.

\section{Marker-trait association}

Out of the 405 SSR markers screened, 250 were polymorphic on the parents and selected progeny. However, some of the polymorphic markers later gave ambiguous allele profiles and were discarded. This left 133 useful markers for marker trait association analyses. Marker and mean genotype SPW BLUPs regression analysis indicated that five out of the 133 SSR markers were significantly associated with field SPW resistance (Table 2). However, the variance $\left(\mathrm{R}^{2}\right.$ values) explained by these markers was low. The most informative SSR marker was J116A, which explained $8 \%$ of the total variance in mean genotype SPW BLUPs.

A total of seven SSR markers were significantly associated with mean storage root HCA ester concentrations in this population (Table 3 ). These markers explained $38.5 \%$ of the total variance in mean HCA ester concentration in the population. The most highly significantly associated SSR marker to HCA ester synthesis in this population was marker IbL10, which explained $7 \%$ of the total variance. SSR markers IBS11, IbE5 and IbJ544b were significantly associated with both HCA ester and field-based SPW resistance in this population.

\section{Discussion}

Sweetpotato weevil damage escalates in SSA sweetpotato fields during dry spells (Stathers et al. 2003). Our results are in agreement with this finding as NaSARRI, located in a semi-arid part of Uganda had the highest mean weevil severity. At NaSARRI, dry spells typically begin at the end of the each growing season and are characterized by high levels of soil cracks on the sweetpotato mounds and ridges as the storage roots mature. The soil cracks create entry avenues for gravid weevils to lay eggs in exposed storage roots, which then hatch into larvae, the most damaging stage of the SPW (Jansson et al. 1987). Severe damage by larvae occurs through concealed feeding within the storage roots.

Another reason for SPW escalation during drought is the low amount of water in the soil. As a result, limited amount of water is absorbed and transported throughout the plants and the plants consequently dry up (Mao et al. 2004). Therefore, the translocation of plant defense phytochemicals throughout the plant is also inhibited due to the low amount of water flowing through the vascular tissues ( $\mathrm{Ni}$ et al. 2009). The significant $G \times E$ interaction for SPW resistance observed in our study implies that genotypes should be tested at multiple sites for selecting SPW resistance.

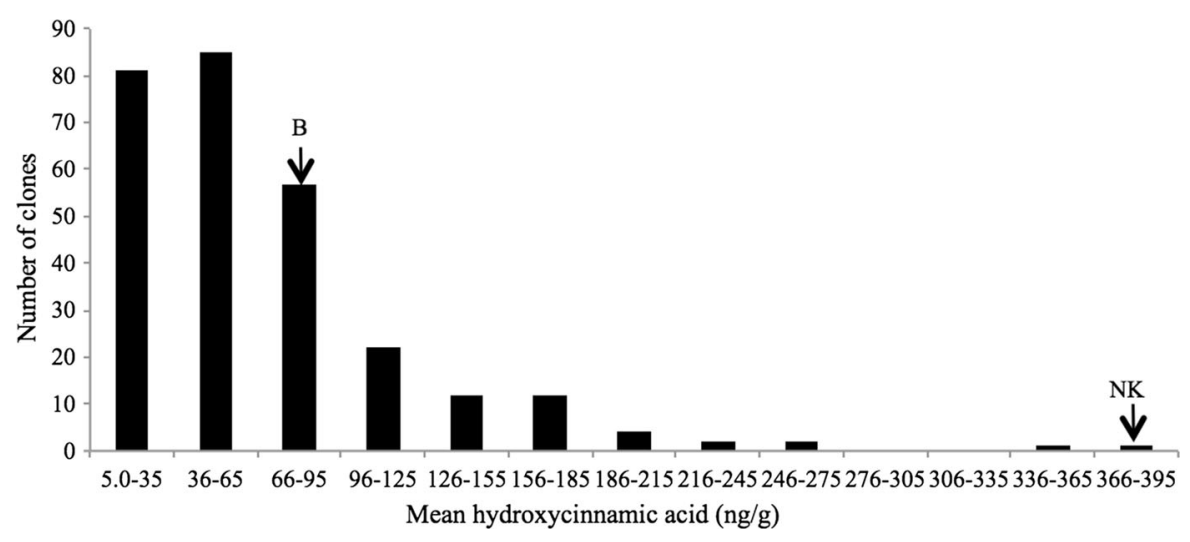

Fig. 2 Distribution of mean storage root hydroxycinnamic acid ester content in the progeny and parents of the 'New Kawogo' (NK) x 'Beauregard' (B) across sites, bars represent the number of clones in each class of mean storage root hydroxycinnamic acid ester content scores averaged over sites 
Table 2 Association of SSR markers with the best linear unbiased predictions of overall mean across-sites and seasons sweetpotato weevil severity (SPW_BLUPS) of genotypes

\begin{tabular}{|c|c|c|c|c|c|c|}
\hline Marker $^{\mathrm{a}}$ & Number of alleles & Most significant allele ${ }^{\mathrm{b}}$ & $\mathrm{R}^{2}$ & SPW_BLUP mean & $\mathrm{F}$ value & ProbF \\
\hline J116A & 5 & J116ANKB210 & 0.0806 & 0.0006 & 4.68 & 0.000 \\
\hline IbL16 & 5 & IbL16NK183 & 0.0446 & 0.0024 & 2.56 & 0.028 \\
\hline IBS11 & 5 & IBS11NKB253 & 0.0443 & 0.0006 & 2.48 & 0.032 \\
\hline IbE5 & 3 & IbE5B218 & 0.0311 & 0.0024 & 2.95 & 0.033 \\
\hline $\mathrm{IbO5}$ & 2 & IbO5NKB181 & 0.0233 & 0.0024 & 3.31 & 0.038 \\
\hline
\end{tabular}

$R^{2}$ Proportion of SPW severity variance explained by SSR markers

a SSR markers that were highly associated with SPW resistance selected out of 133 SSRs analyzed in the study

b Marker allele that had the highest significant association with resistance and also the allele that accounted for the highest variance for SPW resistance

Table 3 Association of SSR marker loci with the best linear unbiased predictions of overall mean across-sites hydroxycinnamic acid (HCA_BLUPS) concentration of genotypes

\begin{tabular}{|c|c|c|c|c|c|c|}
\hline Marker $^{\mathrm{a}}$ & Number of alleles & Most significant allele ${ }^{\mathrm{b}}$ & $\mathrm{R}^{2}$ & HCA_BLUP mean & $\mathrm{F}$ value & ProbF \\
\hline IbL10 & 5 & IbL10B197 & 0.0671 & 0.00248 & 8.60 & 0.004 \\
\hline IBS62 & 5 & IBS62B 120 & 0.0654 & 0.0023 & 8.50 & 0.004 \\
\hline IbE5 & 3 & IbE5B218 & 0.0580 & 0.0024 & 2.84 & 0.011 \\
\hline IBSSR03 & 6 & IBSSR03B219 & 0.0525 & 0.002386 & 2.15 & 0.039 \\
\hline IBS11 & 5 & IBS11NKB253 & 0.0510 & 0.0006 & 2.73 & 0.023 \\
\hline IbJ544b & 4 & IbJ544bNKB 197 & 0.0460 & 0.0032 & 2.40 & 0.030 \\
\hline IbL16 & 5 & IbL16NK183 & 0.0446 & 0.0024 & 2.56 & 0.028 \\
\hline
\end{tabular}

$R^{2}$ Proportion of HCA ester concentration variance explained by SSR markers

a SSR markers that were highly associated with HCA based weevil resistance selected out of 133 SSRs analyzed in the study

b Marker allele that had the highest significant association with HCA_BLUPS and also the allele that accounted for the highest variance for HCA based resistance

The genotypes (progeny and parents) in our study significantly differed in their mean weevil infestation across sites and seasons. Their published levels of SPW resistance informed our choice of the parental genotypes used in this study. 'New Kawogo' was reported to be moderately resistant and have high levels of plant chemicals conferring field resistance to SPW (Mwanga et al. 2001; Stevenson et al. 2009), whereas 'Beauregard' was reported to be highly susceptible to a host of insect pests including sweetpotato weevils (Rolston et al. 1987). Furthermore, we report here comparatively low levels of HCAs for 'Beauregard'.

We observed a range of field SPW resistance in this population. The large number of progeny showing transgressive segregation is attributed to the diverse nature of the parents selected from different gene pools. Grüneberg et al. (2009) reported that progeny generated from diverse parents from wide gene pools exhibited high levels of diversity and heterosis for key agronomic traits in sweetpotato. Progeny that performed better than 'New Kawogo' and had storage root yield have become potential candidates for yield trials and use as sources of genes for future population improvement. A moderately high level of genetic diversity was observed in this population (Yada et al. 2015), which supports the observation of the large number of progeny exhibiting transgressive segregation for SPW resistance.

The significant differences in the concentrations of mean total HCA esters among the genotypes could be attributed to random re-assortment of alleles at multiple loci for this trait in this cross. 'New Kawogo' (female) was reported to have high concentrations of total HCA esters and high levels of field resistance to SPW (Stevenson et al. 2009; Anyanga et al. 2013). 
Total HCA esters were reported to have a significant effect on the mortality of sweetpotato weevils in a controlled laboratory experiment on treated artificial diet in a dose dependent response, which is the reason they were hypothesized to be the chemical basis of active and quantifiable SPW resistance in 'New Kawogo' (Stevenson et al. 2009).

The highly skewed distribution of mean HCA ester concentration of genotypes to the right with a mean genotype HCA ester concentration of $69.4 \mathrm{ng} / \mathrm{g}$ could be an indication of a rare allele that is qualitatively and recessively inherited. However, we cannot draw this conclusion with the sample size that was used in this study. Hydroxycinnamic acid esters have been shown to play key roles in the biosynthesis pathway of lignin, a key mode of plant defense against pathogenic attack and herbivory (Boerjan et al. 2003). Single genes were isolated and shown to encode the enzymes for lignin biosynthesis including hydroxycinnamate CoA ligase (4CL) in sugarcane (Ramos et al. 2001). The mode of inheritance of HCA esters in sweetpotato needs to be understood for enhancing their application in improving SPW resistance.

A few clones including NKB152, NKB257, NKB108, NKB59 and NKB60, from our study showed consistently high levels of field and HCA ester-based weevil resistance. These clones could be candidate parental genotypes for use in population improvement for SPW resistance in SSA. We also observed clones that showed high levels of field resistance in terms of their weevil damage scores but contrarily had low HCA ester concentrations (e.g. NKB72, NKB225, NKB52, NKB158 and NKB279). The resistance in these particular clones could be attributed to other defense mechanisms than HCA synthesis such as: deep rooting, presence of physical morphological barriers (i.e., heavy pubescence) and quick healing mechanisms to insect wounding. These genotypes could have exhibited escape instead of active SPW resistance through mechanisms such as deep rooting. Varieties with deep rooting and heavy pubescence characteristics were reported to sustain low SPW damage in SSA (Stathers et al. 2003). The low field SPW damage in these genotypes could additionally have been attributed to presence of thick storage root cortex. Stathers et al. (2003) reported that, sweetpotato weevils less damaged genotypes with thick storage root cortex. Thick storage root cortex could lessen feeding as well as egg laying in weevils.
It is noteworthy that some cultivars, for example 'Ruddy' (Bohac et al. 2002), 'Regal' (Jones et al. 1985) and 'Sumor' (Dukes et al. 1987), which are resistant to key insect pests, including the WirewormDiabrotica-Systena (WDS) complex and C. formicarius have been released in the US, though they have not become commercially important. To date, no SPW resistant cultivar has been bred and released in SSA despite the rigorous screening for SPW resistance in the global sweetpotato germplasm (Hahn and Leuschner 1981; Thompson et al. 1999; Yada et al. 2011; Jackson et al. 2012; Muyinza et al. 2012). Apart from the limited sources of SPW resistance for sweetpotato improvement in SSA, dual infestation by $C$. puncticollis and C. brunneus is another challenge to these efforts. The identification of progeny showing high levels of positive transgressive segregation resistance against both Cylas spp. could present a positive effort to address SPW damage in the region.

From our study, the broad sense heritability of SPW resistance was moderate $\left(\mathrm{H}^{2}=0.49\right)$, meaning a substantial amount of SPW resistance in this population is due to genetic variance. The inheritance of SPW resistance has been poorly studied. Thompson et al. (1994) in a set of half-sib families of 19 parental genotypes of varying levels of SPW resistance estimated the narrow sense heritability of SPW resistance through parent-offspring regression as 0.35 and 0.52 for number of damaged storage roots and percent of storage damaged roots, respectively. The moderate heritability estimate in our study means that selection of increased resistance is achievable, but future families for selecting weevil resistance should be generated from top performing progeny in this population.

The limited number of SSR markers associated with field- and biochemistry-based SPW resistance in our study could be attributed to the moderate heritability of SPW in this population. This is the first time SSR markers are being associated with SPW resistance in sweetpotato to the best of our knowledge. This study has shown that, SSR loci for resistance to SPW occur in sweetpotato and can be used to enhance the improvement of sweetpotato for weevil resistance. The selected SSR markers could be used for genotyping germplasm and selecting diverse SPW resistant parents. However, there is need to identify QTL linked to resistance to SPW for use in sweetpotato improvement.

Future sweetpotato improvement in SSA should exploit the use of HCA ester-based selection 
(chemotyping) augmented with field phenotyping and laboratory bioassays for long term population improvement. However, efforts to develop a low cost chemotyping platform using LC-MS are still too expensive. The calibration of near-infrared spectroscopy (NIRS) for analysis of total HCA ester concentrations in root samples would enhance throughput screening of breeding materials for population improvement in the region. This approach could be possible since fourier-infrared spectroscopy has already been successfully used for quantification of total hydroxycinnamic acid esters in forages (Allison et al. 2009).

In conclusion, our study showed that SPW resistance is a heritable trait that can be mapped with SSR markers. More refined studies for estimating narrow sense heritability for SPW resistance are needed. Field resistance to SPW was significantly influenced by environment; as a result, we recommend further phenotyping of this population for SPW resistance. The positive transgressive segregates need to be screened further to confirm their level of SPW resistance for use in population improvement. Our data needs to be augmented with choice and no-choice feeding bioassay data on the genotypes to draw informed conclusions on the level of SPW resistance in this population. More genomic tools should be developed using the 'New Kawogo' $x$ 'Beauregard' population through genotyping by sequencing of the entire population for SSR and single nucleotide polymorphism (SNP) marker mining.

Acknowledgements The McKnight Foundation Collabo rative Crop Research Program (CCRP) and the Norman E. Borlaug Leadership Enhancement in Agriculture Program (LEAP) funded this research. Dr. Consuelo Arellano of the Department of Statistics, NCSU is acknowledged for providing guidance in statistical data analysis. We also thank the research staff at the various institutes for their support.

\section{Compliance with ethical standards}

Conflict of interest The authors declare that they have no conflict of interest.

Open Access This article is distributed under the terms of the Creative Commons Attribution 4.0 International License (http:// creativecommons.org/licenses/by/4.0/), which permits unrestricted use, distribution, and reproduction in any medium, provided you give appropriate credit to the original author(s) and the source, provide a link to the Creative Commons license, and indicate if changes were made.

\section{References}

Allison GG, Thain SC, Morris P, Morris C, Hawkins S, Hauck B, Barraclough T, Yates N, Shield I, Bridgwater AV, Donnison IS (2009) Quantification of hydroxycinnamic acids and lignin in perennial forage and energy grasses by Fourier-transform infrared spectroscopy and partial least squares regression. Bioresour Technol 100:1252-1261

Anyanga MO, Muyinza H, Talwana H, Hall DR, Farman DI, Ssemakula GN, Mwanga ROM, Stevenson PC (2013) Resistance to the weevils Cylas puncticollis and Cylas brunneus Conferred by sweetpotato root surface compounds. J Agric Food Chem 61:8141-8147

Boerjan W, Ralph J, Baucher M (2003) Lignin biosynthesis. Annu Rev Plant Biol 54:519-546

Bohac JR, Jackson DM, Dukes PD, Mueller JD (2002) 'Ruddy': a multiple pest resistant sweetpotato. HortScience 37:993-994

Buteler MI, Jarret RL, LaBonte DR (1999) Sequence characterization of microsatellites in diploid and polyploid Ipomoea. Theor Appl Genet 99:123-132

Cervantes-Flores JC, Yencho GC, Kriegner A, Pecota KV, Faulk MA, Mwanga ROM, Sosinski B (2008a) Development of a genetic linkage map and identification of homologous linkage groups in sweetpotato using multipledose AFLP markers. Mol Breed 21:511-532

Cervantes-Flores JC, Yencho GC, Pecota KV, Sosinski B, Mwanga ROM (2008b) Detection of quantitative trait loci and inheritance of root-knot nematode resistance in sweetpotato. J Am Soc Hortic Sci 133:844-851

Cervantes-Flores JC, Sosinski B, Pecota KV, Mwanga ROM, Catignani GL, Truong VD, Watkins RH, Ulmer MR, Yencho GC (2011) Identification of quantitative trait loci for dry-matter, starch, and $\beta$-carotene content in sweetpotato. Mol Breed 28:201-216

Chang K, Lo H, Lai Y, Yao P, Lin K, Hwang S (2009) Identification of quantitative trait loci associated with yield-related traits in sweetpotato (Ipomoea batatas). Bot Stud 50:43-50

Cockerham KL, Deen OT, Christian MB, Newson L (1954) Biology of the sweetpotato weevil. Louisiana Agric Exp Stn Tech Bull No 483

Doyle JJ, Doyle JL (1990) Isolation of plant DNA from fresh tissue. Focus 12:13-15

Dukes PD, Hamilton MG, Jones A, Schalk JM (1987) ‘Sumor', a multi-use sweetpotato. HortScience 22:170-171

FAOSTAT (2014) Food and Agricultural Organization of the United Nations, Production statistics (http://faostat.fao. org/). Accessed Aug 2015

Grüneberg WJ, Mwanga R, Andrade M, Dapaah H (2009) Sweetpotato breeding. In: Andrade M, Barker I, Cole D, Dapaah H, Elliott H, Fuentes S, Gruneberg WJ, Kapinga R, Kroschel J, Labarta R, Lemaga B, Loechl C, Low J, Lynam J, Mwanga R, Ortiz O, Oswald A, Thiele G (eds) Unleashing the potential of sweetpotato in sub-Saharan Africa: current challenges and way forward Nairobi, CIPSSA

Grüneberg WJ, Eyzaguirre R, Espinoza J, Mwanga ROM, Andrade M, Dapaah H, Tumwegamire S, Agili S, NdingoChipungu FP, Attaluri S, Kapinga R, Nguyen T, Kaiyung 
X, Tjintokohadi K, Carey EE, Low J (2010) Procedures for the evaluation and analysis of sweetpotato trials. International Potato Center, Lima

Hahn SK, Leuschner K (1981) Resistance of sweetpotato cultivars to African sweetpotato weevil. Crop Sci 21:499-503

Hotz C, Loechl C, Lubowa A, Tumwine JK, Ndeezi G, Masawi AN, Baingana R, Carriquiry A, De Brauw A, Meenakshi JV, Gilligan DO (2012) Introduction of $\beta$-carotene-rich orange sweetpotato in rural Uganda resulted in increased vitamin A intakes among children and women and improved vitamin A status among children. J Nutr 142:1871-1880

Hu J, Nakatani M, Mizuno K, Fujimura T (2004) Development and characterization of microsatellite markers in sweetpotato. Breed Sci 58:177-188

Jackson DM, Harrison HF, Ryan-Bohac JR (2012) Insect resistance in sweetpotato plant introduction accessions. J Econ Entomol 105:651-658

Jansson RK, Brayn HH, Sorensen KA (1987) Within-vine distribution and damage of the sweetpotato weevil Cylas formicarius elengantulus (Coleoptera: Curculionidae), on four cultivars of sweetpotato in southern. Fla Entomol 70:523-526

Jones A, Dukes PD, Schalk JM, Hamilton MG, Mullen MA, Baumgardner RA, Paterson DR, Boswell TE (1985) 'Regal' sweetpotato. HortScience 20:781-782

Karyeija RF, Gibson RW, Valkonen JPT (1998) The significance of sweetpotato feathery mottle virus in subsistence sweetpotato production in Africa. Plant Dis 82:4-15

Low JW, Arimond M, Osman N, Cunguara B, Zano F, Tschirley D (2007) A Food-based approach introducing orange-fleshed sweetpotatoes increased vitamin A intake and serum retinol concentrations in young children in rural Mozambique. J Nutr 137:1320-1327

Mao L, Jett LE, Story RN, Hammond AM, Peterson JK, LaBonte DR (2004) Influence of drought stress on sweetpotato resistance to sweetpotato weevil, Cylas formicarius (Coleoptera: Apoinidae), and storage root chemistry. Fla Entomol 83:261-267

Muyinza H, Talwana HL, Mwanga ROM, Stevenson PC (2012) Sweetpotato weevil (Cylas spp.) resistance in African sweetpotato germplasm. Int J Pest Manag 58:73-81

Mwanga ROM, Odongo B, Ocitti p'Obwoya C, Gibson RW, Smit NEJM, Carey EE (2001) Release of five sweetpotato cultivars in Uganda. HortScience 36:385-386

Ni F-T, Chu L-Y, Shao H-B, Liu Z-H (2009) Gene expression and regulation of higher plants under soil water stress. Curr Genom 10:269-280

Nottingham SF, Kays SJ (2002) Sweetpotato weevil control. Acta Hortic 583:155-161

Odongo B, Heather K, Ewell P, Stathers T, van de Fliert E, Mudiope J, Ogiro V, Lugwana E (2003) Techniques of re-hilling sweetpotato mounds to reduce Cylas spp. weevil infestation and improve sweetpotato yield in Soroti district, northeastern Uganda. Uganda J Agric Sci 8:117-122

Ramos RLB, Tovar FJ, Junqueira RM, Lino FB, SachettoMartins G (2001) Sugarcane expressed sequences tags (ESTs) encoding enzymes involved in lignin biosynthesis pathways. Genet Mol Biol 24:235-241
Rolston LH, Clarke CA, Cannon JM, Randle WM, Riley EG, Wilson PW, Robbins ML (1987) "Beauregard" sweetpotato. HortScience 22:1338-1339

Sato K, Uritani I (1981) Characterization of the terpene-inducing factor isolated from the larvae of the sweetpotato weevil, Cylas formicarius Fabricius (Coleoptera: Brentidae). Appl Entomol Zool 16:103-112

Schafleitner R, Tincopa LR, Palomino O, Rossel G, Robles RF, Alagon R, Rivera C, Quispe C, Rojas L, Pacheco JA, Solis J, Cerna D, Kim JY, Hou J, Simon R (2010) A sweetpotato gene index established by denovo assembly of pyrosequencing and Sanger sequences and mining for gene-based microsatellite markers. BMC Genom 11:604

Smit NEJM (1997) Integrated pest management for sweetpotato in Eastern Africa. PhD Thesis, Agricultural University Wageningen

Stathers TE, Rees D, Nyango A, Kiozya H, Mbilinyi L, Jeremiah S, Kabi S, Smit N (2003) Sweetpotato infestation by Cylas spp in East Africa: I Cultivar differences in field infestation and the role of plant factors. Int J Pest Manag 49:131-140

Stevenson PC, Muyinza H, Hall DR, Porter EA, Dudley I, Farman DI, Talwana H, Mwanga ROM (2009) Chemical basis for resistance in sweetpotato Ipomoea batatas to the sweetpotato weevil, Cylas puncticollis. Pure Appl Chem $81: 141-151$

Teow CC, Troung V-D, McFeeters Thompson RL, Pecota KV, Yencho CG (2007) Antioxidant activities, phenolic and $\beta$ carotene contents of sweet potato genotypes with varying flesh colours. Food Chem 103:829-838

Thompson PG, Schneider JC, Graves B (1994) Genetic variance components and heritability estimates of freedom from weevil injury to sweetpotato. J Am Soc Hortic Sci 119:620-623

Thompson PG, Schneider JC, Graves B, Sloan RC (1999) Insect resistance in sweetpotato plant introductions. HortScience 34:711-714

Tittiger C (2004) Functional genomics and insect chemical ecology. J Chem Ecol 30:2335-2358

Uritani I, Saito T, Honda H, Kim WK (1975) Induction of furanoterpenoids in sweetpotato roots by the larval components of the sweetpotato weevils. Agric Biol Chem 37:1857-1862

van Jaarsveld PJ, Faber M, Tanumihardjo SA, Nestel P, Lombard CJ, Benadé AJS (2005) $\beta$-carotene-rich orange-fleshed sweetpotato improves the vitamin A status of primary school children assessed by the modified-relative-doseresponse test. Am J Clin Nutr 81:1080-1087

Wang Z, Li J, Luo Z, Huang L, Chen X, Fang B, Li Y, Chen J, Zhang X (2011) Characterization and development of EST-derived SSR markers in cultivated sweetpotato (Ipomoea batatas). BMC Plant Biol 11:139

Woolfe JA (1992) Sweetpotato-an untapped food resource. Cambridge University Press, New York

Yada B, Tukamuhabwa P, Alajo A, Mwanga ROM (2011) Field evaluation of Ugandan sweetpotato germplasm for yield, dry matter and disease resistance. S Afr J Plant Soil 28:142-146

Yada B, Brown-Guedira G, Alajo A, Ssemakula GN, Mwanga ROM, Yencho GC (2015) Simple sequence repeat marker analysis of genetic diversity among progeny of a biparental 
mapping population of sweetpotato. HortScience 50:1143-1147

Zhao N, Yu XX, Jie Q, Li H, Li H, Hu J, Zhai H, He SZ, Li QC

(2013) A genetic linkage map based on AFLP and SSR markers and mapping of QTL for dry-matter content in sweetpotato. Mol Breed 32:807-820 